\title{
Keanekaragaman Kupu-Kupu di Wilayah Pemukiman Desa Pangandaran CIAMIS JAWA BARAT
}

\author{
The Butterflies Diversity in SETtlement Region of The PANGANDARAn ViLlage Ciamis, JawA \\ BARAT
}

\author{
${ }^{1}$ Nurullia Fitriani; ${ }^{2}$ Ani Royani; ${ }^{3}$ Gilang M. Nur Iqbal; ${ }^{4}$ Yumna T. Rahmania \\ ${ }^{1,2,3,4}$ Program Studi Biologi Universitas Padjadjaran \\ Email: ${ }^{1}$ kanoefit_88@yahoo.com
}

\begin{abstract}
Butterflies are insects of the order Lepidoptera most widely known through the shape and color of the wings. Butterflies are found in a variety of ecosystems including the settlement in the village of Pangandaran bordering the Pangandaran Nature Reserve. This study aims to determine the diversity of butterflies in a residential area of Pangandaran. The method used in this study is a survey by exploration around the locality. Observations were made every day at 08.00 to 17.00 during the week. Butterflies are found to be captured by using insect net and preserved for the sake of identification. In this study, also conducted measurements of environmental parameters such as temperature, humidity, light intensity and wind speed as well as a recording of plant species in the vicinity of the study. The data were analyzed descriptively. The results show there are seven species of butterflies from the family nymphalid, four species of family papilonidae and nine species of the family Pieridae.
\end{abstract}

Keywords: diversity, butterflies, survey

\begin{abstract}
Abstrak. Kupu-kupu merupakan serangga dari ordo lepidoptera yang paling banyak dikenal melalui bentuk dan warna sayapnya. Kupu-kupu banyak ditemukan di berbagai ekosistem termasuk pemukiman di Desa Pangandaran yang letaknya berbatasan dengan Cagar Alam Pangandaran. Penelitian ini bertujuan untuk mengetahui keanekaragaman kupu-kupu di wilayah pemukiman Pangandaran. Metode yang digunakan pada penelitian ini adalah survey dengan melakukan penjelajahan di seluruh wilayah pemukiman. Pengamatan dilakukan setiap hari pada pukul 08.00 sampai dengan pukul 17.00 selama seminggu. Kupu-kupu yang ditemukan ditangkap dengan menggunakan insect net dan diawetkan untuk kepentingan identifikasi. Pada penelitian ini juga dilakukan pengukuran parameter lingkungan berupa suhu, kelembaban, intensitas cahaya dan kecepatan angin serta pencatatan jenis tumbuhan di sekitar lokasi penelitian.. Analisis data dilakukan secara deskriptif. Dari hasil penelitian diketahui terdapat 7 species kupu-kupu dari family nympalidae, 4 species dari family papilonidae dan 9 species dari family pieridae.
\end{abstract}

Kata kunci : keanekaragaman, kupu-kupu, survey

\section{Pendahuluan}

Indonesia merupakan negara yang memiliki keanekaragaman tumbuhan dan hewan yang tinggi termasuk keanekaragaman kupu-kupu. Peggie (2008) menyatakan bahwa Indonesia memiliki sekitar 1.600 species kupu-kupu yang tersebar di seluruh Indonesia. 
Selain itu, Indonesia memiliki tingkat endemisitas kupu-kupu yang tinggi, $35 \%$ dari total kupu-kupu yang ada di Indonesia merupakan kupu-kupu endemik.

Kupu-kupu merupakan serangga dari ordo lepidoptera atau serangga bersayap sisik. Kupu-kupu mudah dikenali karena memiliki bentuk dan warna sayap yang indah. Kupu-kupu merupakan fase dewasa dari ordo lepidoptera, fase lainnya dalam siklus hidup kupu-kupu adalah telur dan larva. Kupu-kupu dapat hidup hampir di setiap ekosistem, baik yang beriklim panas sampai yang beriklim dingin, dari dataran rendah sampai dataran tinggi.

Keanekaragaman kupu-kupu dipengaruhi oleh beberapa faktor lingkungan dan vegetasi seperti inang dan pakan. Kupu-kupu menyukai cuaca yang hangat dan udara yang bersih. Kupu-kupu menjadi aktif pada pagi atau sore hari saat cuaca cerah. Pada udara yang terlalu panas, biasanya kupu-kupu akan beristirahat dan bernaung pada tumbuhan. Kupu-kupu merupakan serangga penyerbuk yang secara ekologis berperan dalam keseimbangan ekosistem. Selain itu, karena sifatnya yang sensitif terhadap perubahan lingkungan, kupu-kupu dapat digunakan sebagai bioindikator kualitas lingkungan.

Pangandaran merupakan daerah wisata yang menjadi favorit bagi masyarakat Jawa Barat. Kedatangan wisatawan ke daerah ini menyebabkan tingkat perubahan lingkungan yang tinggi. Perubahan lingkungan terutama di desa Pangandaran dapat dilihat dari perubahan tata guna lahan dari ruang terbuka menjadi daerah pemukiman dan hotel-hotel. Perubahan lingkungan ini, sangat berdampak terhadap keanekaragaman kupu-kupu yang ada di Desa Pangandaran.

Penelitian ini bertujuan untuk mengetahui keanekaragaman kupu-kupu di pemukiman Desa Pangandaran. Data keanekaragaman ini sangat penting untuk memonitoring perubahan lingkungan yang terjadi sehingga pada tahun yang akan datang, data keanekaragaman ini dapat digunakan untuk acuan kebijakan dalam konservasi daerah Pangandaran.

\section{Metode Penelitian}

Penelitian kupu-kupu ini dilakukan dengan metode survey yaitu menjelajahi rute atau jalan di sekitar Desa Pangandaran. Tehnik pengumpulan kupu-kupu dilakukan dengan menggunakan jaring serangga. Penelitian dilakukan setiap hari pada cuaca cerah pada pukul 08.00 - 17.00 selama satu minggu. Kupu-kupu yang tertangkap akan dikoleksi dan diawetkan untuk diindentifikasi.

Kupu-kupu yang tertangkap dimasukkan ke dalam kertas papilot untuk penyimpanan sementara. Proses pengawetan dilakukan dengan cara menyuntikkan alkohol $70 \%$ pada bagian dada atas kupu-kupu. Kupu-kupu yang telah diawetkan kemudian ditusuk menggunakan insect pin pada bagian atas secara tegak lurus dan sayapnya direntangkan pada papan perentang. Specimen awetan ini didiamkan dan ditahan dengan menggunakan kertas minyak sampai sayapnya menjadi kaku. Setelah sayap menjadi kaku, awetan kupu-kupu dipindahkan ke dalam kotak insektarium. Awetan kupu-kupu ini digunakan untuk mempermudah proses identifikasi di laboratorium.

Pada penelitian ini juga dilakukan pengukuran parameter lingkungan yaitu suhu dan kelembaban udara, intensitas cahaya serta kecepatan angin. Pengukuran dilakukan dengan menggunakan digital air measurement Luxtron. Selain itu, dilakukan pencatatan jenis tumbuhan di lokasi penelitian. Analisis data dilakukan secara deskriptif yaitu dengan cara menggambarkan keanekaragaman kupu-kupu di lokasi penelitian. 


\section{Hasil dan Pembahasan}

\section{Kondisi Lingkungan dan Vegetasi}

Rata-rata suhu udara di lokasi penelitian adalah $31,73^{\circ} \mathrm{C}$ dengan kelembaban rata-rata sebesar $73,56 \%$. Kupu-kupu menyukai suhu yang hangat berkisar antara $28{ }^{\circ} \mathrm{C}$ - $35{ }^{\circ} \mathrm{C}$ dengan kelembaban optimal $60 \%$ - $75 \%$. Pada suhu dan kelembaban yang terlalu rendah atau terlalu panas biasanya kupu-kupu menjadi tidak aktif bahkan mengalami kematian. Kupu-kupu juga sangat dipengaruhi oleh kecepatan angin, kupukupu tidak menyukai kecepatan angin yang tinggi karena mempengaruhi aktifitas terbangnya terutama kupu-kupu bersayap lebar, pada kecepatan angin yang tinggi, biasanya sayap mengalami kerusakan. Kecepatan angin di lokasi penelitian adalah $0-1$ $\mathrm{m} / \mathrm{s}$ dengan rata-rata $0,6 \mathrm{~m} / \mathrm{s}$.

Faktor lingkungan lain yang mempengaruhi kupu-kupu adalah intensitas cahaya. Intensitas cahaya akan mempengaruhi kemampuan kupu-kupu untuk melihat dan terbang. Rata-rata intensitas cahaya di lokasi penelitian adalah 18190 lux. Cahaya akan memberikan energi panas pada kupu-kupu sehingga suhu tubuhnya meningkat dan metabolisme dalam tubuh berlangsung lebih cepat. Data faktor lingkungan di lokasi penelitian disajikan pada tabel 1 .

Tabel 1. Parameter Lingkungan Terukur

\begin{tabular}{|l|c|}
\hline \multicolumn{1}{|c|}{ Parameter Lingkungan } & Rata-rata \\
\hline Suhu $\left({ }^{\circ} \mathrm{C}\right)$ & 31,73 \\
\hline Kelembaban udara (\%) & 73,56 \\
\hline Kecepatan angin (m/s) & 0,6 \\
\hline Intensitas cahaya (lux) & 18190 \\
\hline
\end{tabular}

Terdapat 32 jenis tanaman di lokasi penelitian diantaranya adalah Stachytarpheta jamaicensis, Musa paradisiaca, Tamarindus indica, Cordilyne fructicosa, Ixora javanica, Plumeria obtusa, Bougenvilia sp., Rosa sp., Syzygium aqneum, Psidium guajava, Hibiscus tiliaceus, Cytrus sp., dan Mangifera indica.

\section{Keanekaragaman Kupu-kupu}

Terdapat 3 family ditemukan di lokasi penelitian yaitu Nympalidae, Papilonidae dan Pieridae. Pieridae merupakan family yang paling banyak ditemukan yaitu sekitar 45 $\%$, kemudian family Nympalidae sekitar 35\% dan papilionidae sekitar $20 \%$. Family pieridae merupakan family yang jumlah anggota speciesnya cukup banyak dan anggotanya memiliki tanaman inang dan pakan yang bervariasi. Data family kupu-kupu yang ditemukan disajikan pada gambar 1 . 


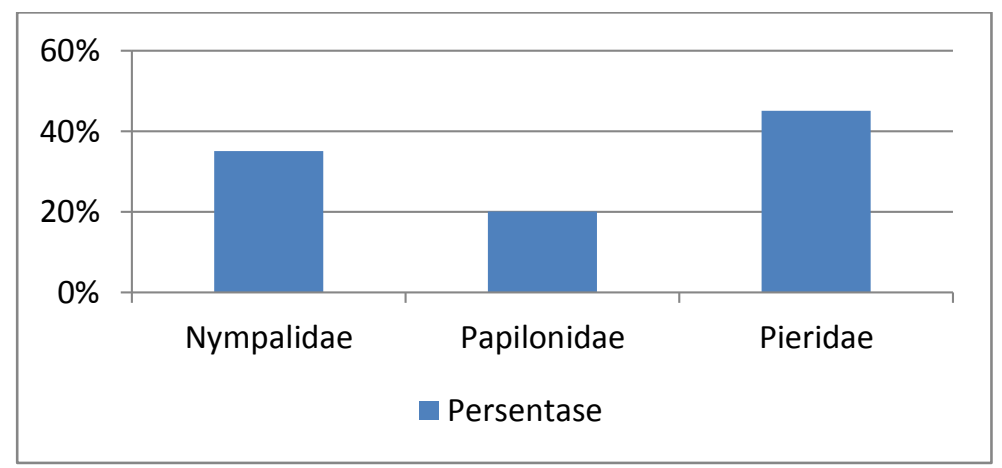

Gambar 1. Family Kupu-kupu yang Ditemukan

\section{[1]. Family Nympalidae}

Ciri utama dari family ini adalah mengecilnya sepasang kaki depan dan pada jantan ditutupi oleh sisik menyerupai sikat sehingga family ini sering disebut dengan the brush-footed (Peggie dan Amir, 2006). Terdapat 7 species dari family nympalidae yang ditemukan yaitu Elymnias nesaea, Euthalia adonia, Hypolimnas bolina, Junonia hedonia, Neptis hylas, Phaedyma columella, dan Junonia iphita. Gambar kupu-kupu dari family ini disajikan pada gambar 2 .

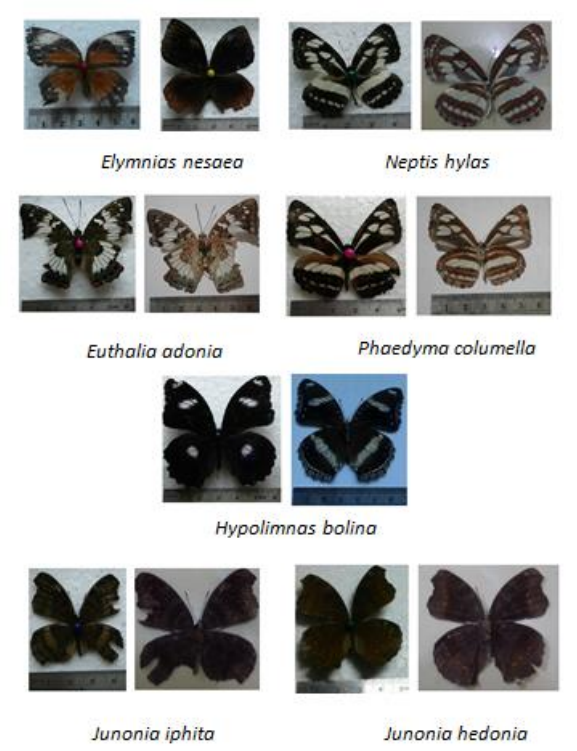

Gambar 2. Kupu-kupu Family Nympalidae (Tampak Dorsal dan Ventral)

\section{[2]. Family Papilionidae}

Anggota family papilionidae biasanya memiliki sayap yang lebar. Sayap memiliki satu atau dua warna mencolok dengan latar belakang hitau atau coklat kehitaman. Beberapa anggota family ini memiliki ekor yang merupakan kepanjangan dari sayap belakang. Kupu-kupu ini dikenal dengan istilah birdwing atau swallowtail (Noerdjito dan Answari, 2003).

Kupu-kupu family papilonidae yang ditemukan sebanyak 4 species yaitu Graphium agamemnon, Papilio memnon, Papilio demoleus dan Papilio polytes. Gambar dari family papilionidae ini disajikan pada gambar 3. 


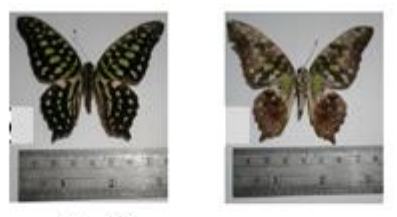

Graphium agamemnon

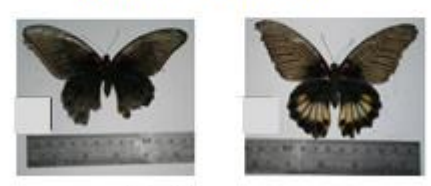

Papilio memnon

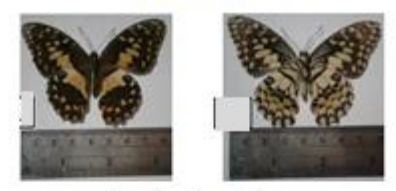

Papilio demoleus

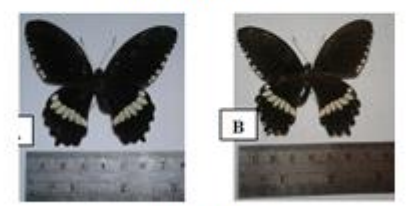

Papilio polytes

Gambar 3. Kupu-kupu Family Papilionidae ( Tampak Dorsal dan Ventral)

\section{[3]. Family Pieridae}

Davies dan Butler (2008) mengatakan bahwa kupu-kupu dari family pieridae berwarna kuning dan putih. Tetapi ada juga kupu-kupu dari family ini berwarna orange dengan sedikit hitam atau merah. Ukuran sayap family ini, kecil sampai dengan sedang.

Kupu-kupu family pieridae biasanya terbang berkelompok dan biasanya berjumlah banyak. Pada siang dan sore hari sekitar pukul 9.00 sampai dengan pukul 11.00 dan pukul 15.00 sampai pukul 17.00, aktifitas terbang menjadi lebih aktif dan beberapa species biasanya terbang lebih tinggi.

Terdapat 9 species ditemukan di Desa Pangandaran yaitu Appias lyncida, Appias olferna, Catopsilia pyranthe, Delias periboea, Eurema alitha, Eurema blanda, Eurema hacabe, Eurema sari dan Lapotosia nina. Gambar kupu-kupu dari family ini disajikan pada gambar 4. 


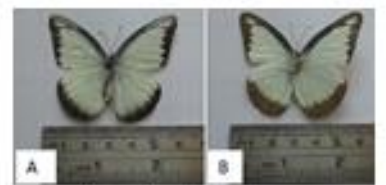

Appias lyncida

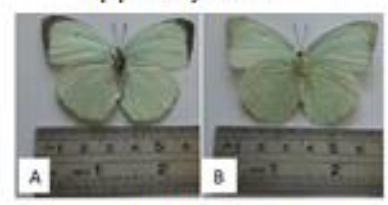

Catopsilia pyranthe

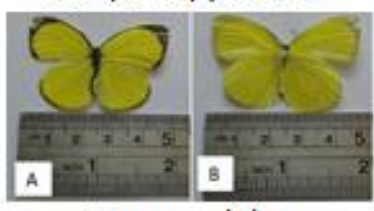

Eurema alitha

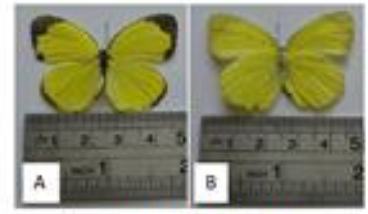

Eurema hacabe

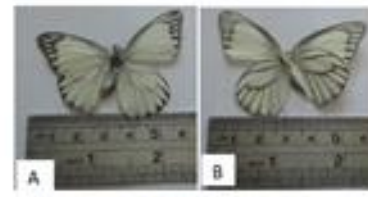

Appias olferna

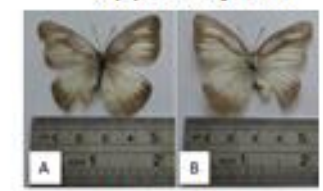

Delias periboea

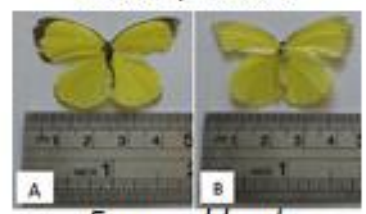

Eurema blanda

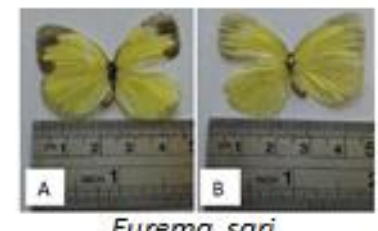

Eurema sari

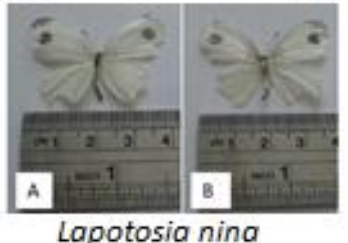

Gambar 4. Kupu-kupu Family Pieridae (Tampak Dorsal dan Ventral)

\section{Kesimpulan}

Keanekaragaman kupu-kupu di Desa Pangandaran Ciamis terdiri dari 7 species kupu-kupu dari family nympalidae, 4 species dari family papilonidae dan 9 species dari family pieridae.

\section{Ucapan Terima Kasih}

Ucapan terima kasih penulis sampaikan kepada Direktorat Penelitian dan Pengabdian Kepada Masyarakat Universitas Padjadjaran dan seluruh rekan di Departemen Biologi FMIPA Universitas Padjadjaran

\section{Daftar pustaka}

Borror, D.J., Triplehorn, C.A., Jhonson, N.F. 1992. Pengenalan Pelajaran Serangga. Diterjemahkan oleh drh. Soetiyono P. Gadjah Mada University Press. Yogyakarta.

Braby, M.f. 2000. Butterflies of Australia. Their Identification, Biology, and Distribution. SCRIO Publishing. Melbourne.Coonors, J. 2002. Butterfly in Your Backyard. North Carolina State University. Carolina.

Davies, H. and Carol A. Butler. 2008. Do Butterfly Bite. Rutgers University Press: New Jersey 
54 | Nurullia Fitriani, et al.

Dyer, J.A. 2006. Raising Awareness Among canadians About Plant Pollinatori and The Immportance of Monitoring and Conserving Them. Seed of Diversity Press: Canada. Noerdjito, W. A dan Aswari, P. 2003. Metode Survei dan Pemantauan Populasi Satwa Seri Keempat Kupu-kupu Papilionidae. Puslit Biologi LIPI Cibinong. Bogor.

Peggie, D. dan Amir, M. 2006. Panduan Praktis Kupu-kupu di Kebun Raya Bogor. LIPI Press. Bogor.

Peggie, D. 2008. Кири-kири, Keunikan Tiada Tara. (Online). http://biologi.lipi.go.id/bio_indonesian/mTemplate.php?h=3\&id_berita=32. Diakses pada tanggal 31 Desember 2015 pukul 20:10 WIB.

Thekayyam, S. G. 2009. Ornamental plants. Sumit pal jain: India. 